\title{
Strong Acid-Nonionic Surfactant Lyotropic Liquid-Crystalline Mesophases as Media for the Synthesis of Carbon Quantum Dots and Highly Proton Conducting Mesostructured Silica Thin Films and Monoliths
}

\author{
Elif B. Olutaş, ${ }^{\dagger \dagger}$ Fadime M. Balc1, ${ }^{\dagger}$ and Ömer Dag ${ }^{*}{ }^{\dagger}$ \\ ${ }^{\dagger}$ Bilkent University, Department of Chemistry, 06800 Ankara, Turkey \\ ${ }^{\ddagger}$ Department of Chemistry, Abant İzzet Baysal University, 14280 Bolu, Turkey
}

Supporting Information

\begin{abstract}
Lyotropic liquid-crystalline (LLC) materials are important in designing porous materials, and acids are as important in chemical synthesis. Combining these two important concepts will be highly beneficial to chemistry and material science. In this work, we show that a strong acid can be used as a solvent for the assembly of nonionic surfactants into various mesophases. Sulfuric acid (SA), 10-lauryl ether $\left(\mathrm{C}_{12} \mathrm{E}_{10}\right)$, and a small amount of water form bicontinuous cubic $\left(\mathrm{V}_{1}\right), 2 \mathrm{D}-$ hexagonal $\left(\mathrm{H}_{1}\right)$, and micelle cubic $\left(\mathrm{I}_{1}\right)$ mesophases with increasing SA/ $\mathrm{C}_{12} \mathrm{E}_{10}$ mole ratio. A mixture of $\mathrm{SA}$ and $\mathrm{C}_{12} \mathrm{E}_{10}$ is fluidic but transforms to a highly ordered LLC mesophase by absorbing ambient water. The LLC mesophase displays high proton conductivity $(1.5$ to $19.0 \mathrm{mS} / \mathrm{cm}$ at room temperature) that increases with an increasing SA content up to $11 \mathrm{SA} /$ $\mathrm{C}_{12} \mathrm{E}_{10}$ mole ratio, where the absorbed water is constant with respect to the
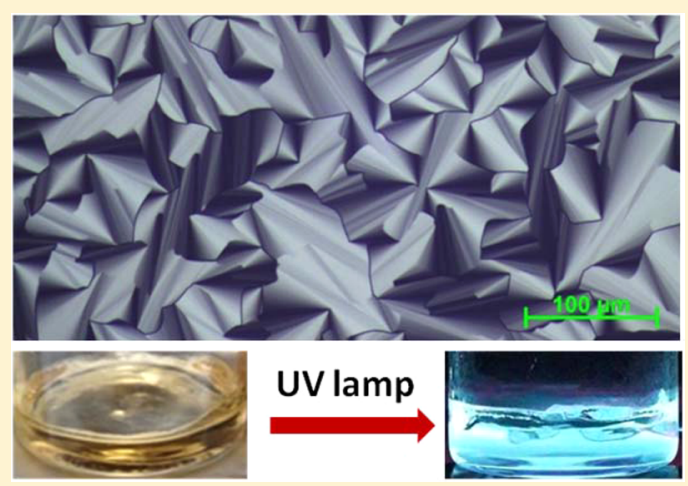
SA amount but gradually increases from a 2.3 to $4.3 \mathrm{H}_{2} \mathrm{O} / \mathrm{C}_{12} \mathrm{E}_{10}$ mole ratio with increasing $\mathrm{SA} / \mathrm{C}_{12} \mathrm{E}_{10}$ from 2 to 11 , respectively. The mixture of $\mathrm{SA}$ and $\mathrm{C}_{12} \mathrm{E}_{10}$ slowly undergoes carbonization to produce carbon quantum dots (c-dots). The carbonization process can be controlled by simply controlling the water content of the media, and it can be almost halted by leaving the samples under ambient conditions, where the mixture slowly absorbs water to form photoluminescent c-dot-embedded mesophases. Over time the c-dots grow in size and increase in number, and the photoluminescence frequency gradually shifts to a lower frequency. The $\mathrm{SA} / \mathrm{C}_{12} \mathrm{E}_{10}$ mesophase can also be used as a template to produce highly proton conducting mesostructured silica films and monoliths, as high as $19.3 \mathrm{mS} / \mathrm{cm}$ under ambient conditions. Aging the silica samples enhances the conductivity that can be even larger than for the LLC mesophase with the same amount of SA. The presence of silica has a positive effect on the proton conductivity of $\mathrm{SA} / \mathrm{C}_{12} \mathrm{E}_{10}$ systems.
\end{abstract}

\section{INTRODUCTION}

Lyotropic liquid-crystalline (LLC) mesophases of nonionic surfactants form using many different solvents, usually water or organics. ${ }^{1-6}$ Recently, it has also been demonstrated that ionic species such as ionic liquids ${ }^{7-10}$ and various salts ${ }^{11-15}$ can also be used as solvents for the assembly of those surfactants into various mesophases. More recently we have shown that phosphoric acid (PA) also can be used as a solvent to coassemble nonionic surfactants into mesophases, where the PA molecules form a network of hydrogen bonds with each other in the hydrophilic domains of the mesophase and display excellent proton conductivity. ${ }^{16}$ The $\mathrm{PA}-\mathrm{C}_{12} \mathrm{E}_{10}$ mesophase requires some water, but the amount of water is so limited that the conductivity mechanism of the mesophase is mainly based on the hopping mechanism. ${ }^{16}$ Also, the PA is a weak acid, and in the presence of such a small amount of water in the media, it limits the ionic conductivity due to limited solubility. ${ }^{16}$

The LLC mesophases can also be used as a medium for various organic and inorganic reactions that can be carried out in the hydrophilic or hydrophobic domains in confined spaces of those mesophases. ${ }^{17-23}$ Because many organic/inorganic reactions require acidic or basic media, assembling an acidic LLC mesophase is very valuable $e^{24-26}$ for those reactions that may occur with a different mechanism to produce new materials. $^{27}$ Therefore, investigating such reaction media can be unique in the synthesis of organic and inorganic compounds. For instance, concentrated sulfuric acid is used for the decomposition of sugars to carbon nanoparticles. ${ }^{28,29}$ Creating in situ carbon in the LLC mesophases and in porous metal oxides may be beneficial in improving the properties of these materials for various sensing and energy-related applications $^{30-32}$ or in identifying new properties that can lead to new applications.

Received: June 17, 2015

Revised: August 18, 2015

Published: September 2, 2015 
Here, we show a new acidic LLC mesophase that was prepared using a strong acid (sulfuric acid, SA) and a nonionic surfactant (10-lauryl ether, $\left.\mathrm{C}_{12} \mathrm{E}_{10}\right)$. The mixture of these two ingredients usually produces a fluidic gel, where the color of the gel becomes darker over time. This phenomena is well known as the dehydration of organics into carbon. ${ }^{28}$ However, the gel can absorb the ambient water and stabilize it into a relatively rigid ordered mesophase, retaining the carbon quantum dots, likely in the hydrophilic mesodomains. Furthermore, the mesophases have been used for the synthesis of highly proton conducting mesostructured silica thin films and monoliths. The mesophase formation, characterization, and use as a reaction medium, for the c-dot embedded mesophases and highly proton conducting mesostructured silica films, are discussed using data collected from multianalytical techniques.

\section{EXPERIMENTAL SECTION}

Preparation of Lyotropic Liquid-Crystalline (LLC) Mesophases of $\mathrm{SA} / \mathrm{C}_{12} \mathrm{E}_{10}$. The LLC mesophases were prepared using three different methods. In the first method, the samples were prepared by adding the required amount of sulfuric acid $\left(\mathrm{H}_{2} \mathrm{SO}_{4}, 95-\right.$ $98 \%)$ to $1.000 \mathrm{~g}$ of 10-lauryl ether, a nonionic surfactant, to a closed glass vial under ambient conditions at room temperature (RT), 20$25 \%$ relative humidity $(\mathrm{RH})$, and then they were homogenized using a vortex mixer. For example, in the preparation of the $3 \mathrm{SA} / \mathrm{C}_{12} \mathrm{E}_{10}$ mole ratio, $0.494 \mathrm{~g}$ of $\mathrm{H}_{2} \mathrm{SO}_{4}$ was mixed with $1.000 \mathrm{~g}$ of $\mathrm{C}_{12} \mathrm{E}_{10}$. The samples with a mole ratio of 1 to $12\left(\mathrm{H}_{2} \mathrm{SO}_{4} / \mathrm{C}_{12} \mathrm{E}_{10}\right)$ were prepared using the same method. Although the samples were viscous, they also had reasonable fluidity. Each sample was left for at least $12 \mathrm{~h}$ at RT prior to characterization. The gel-like samples were spread on glass slides that absorb atmospheric water under ambient conditions (RT and 20-25\% $\mathrm{RH})$ to obtain LLC mesophases. In the second method, extra water (approximately 1 to $5 \mathrm{H}_{2} \mathrm{O}$ /SA mole ratios) was added to the same samples described above to directly obtain the LLC samples. Since these samples were more rigid gels, they were homogenized by shaking in the water bath at $80{ }^{\circ} \mathrm{C}$ for $24 \mathrm{~h}$. In the last method, the solutions of the same LLC phases were prepared in an excess amount of ethanol or water at RT. In this case, the required amount of $\mathrm{H}_{2} \mathrm{SO}_{4}$ was mixed with excess ethanol or water ( 5 to $10 \mathrm{~mL}$ ), and then $1.000 \mathrm{~g}$ of $\mathrm{C}_{12} \mathrm{E}_{10}$ was added to this solution, which was homogenized by continuously stirring the mixture for 2 to $3 \mathrm{~h}$ at RT. The solutions were coated on glass slides using a spin coater at a speed of 1000 or $2000 \mathrm{rpm}$ to obtain the LLC samples.

Preparation of c-Dot-Embedded LLC Mesophases. To prepare the c-dot-embedded mesophases, a mixture of SA and $\mathrm{C}_{12} \mathrm{E}_{10}$ was aged at $\mathrm{RT}$ or higher temperatures $\left(50\right.$ to $\left.80{ }^{\circ} \mathrm{C}\right)$ for different periods of time. The samples, with aging, change gradually and can be visually monitored by following the color change from colorless to yellow to brown and then to dark brown over time. The cdot formation process is further enhanced by removing water from the medium via drying or heating to a higher temperature (Scheme 1).

Scheme 1. Schematic Representation of the Reaction Path for the c-Dot-Embedded SA/ $\mathrm{C}_{12} \mathrm{E}_{10}$ LLC Mesophases

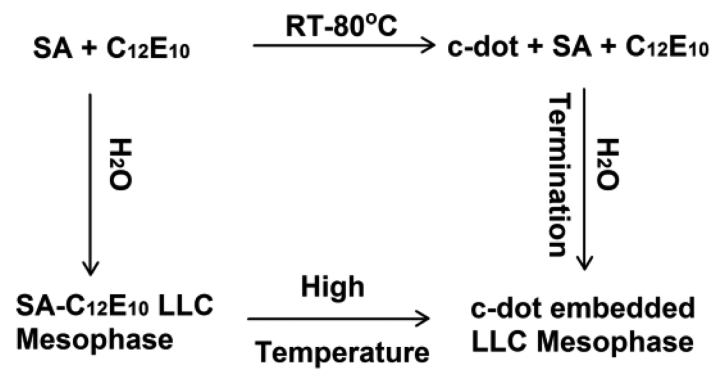

Preparation of SA-Embedded Mesostructured Silica Thin Films and Monoliths. A clear solution of SA/ $\mathrm{C}_{12} \mathrm{E}_{10} / \mathrm{EtOH} / \mathrm{TEOS}$ (TEOS is tetraethylorthosilicate) with a mole ratio of $x: 1: 44: y$ was prepared by adding each component to a vial and then homogenizing by stirring for $15 \mathrm{~min}$. A set of 16 clear solutions were prepared by changing the $x\left(\mathrm{SA} / \mathrm{C}_{12} \mathrm{E}_{10}\right)$ and $y\left(\mathrm{TEOS} / \mathrm{C}_{12} \mathrm{E}_{10}\right)$ from 2 to $8(2,4$, 6 , and 8$)$ and 1 to $7(1,3,5$, and 7$)$, respectively. Then, a few drops of each solution were spin coated or drop cast over a glass substrate to prepare the thin films or monoliths, respectively. The samples were aged at RT for the formation of rigid solid films, and monoliths and aging were monitored using XRD and ac conductivity measurements.

Instrumentation. The XRD patterns were recorded using a Rigaku Miniflex diffractometer equipped with a high-power $\mathrm{Cu} \mathrm{K} \alpha$ source operating at $30 \mathrm{kV} / 15 \mathrm{~mA}$ and a wavelength of $1.5405 \AA$. The POM images were obtained in transmittance mode by using a Zeiss Axio Scope.A1 polarizing optical microscope. The samples were sandwiched between two glass slides and imaged between the crossed polarizers. The melting points were determined using a Linkam LTS350 temperature-controlling stage attached to the same microscope, with a LinkamT95-LinkPad temperature programmer attached to the stage. The cooling of the samples was achieved through the help of liquid $\mathrm{N}_{2}$ in a Dewar connected to the stage and the $\mathrm{N}_{2}$ level of the environment was controlled with a temperature cooling chamber to make a $100 \% \mathrm{~N}_{2}$ environment. The heating and cooling procedures were varied between 1 and 5 degrees/min, and the images of the phase transitions were captured with an built-in camera attached to the top of the microscope. Fourier transform infrared (FT-IR) spectra were recorded using a Bruker Tensor 27 model FTIR spectrometer. A Digi Tect TM DLATGS detector was used with a resolution of $4.0 \mathrm{~cm}^{-1}$ in the $400-4000 \mathrm{~cm}^{-1}$ range. The spectra were recorded by spreading the samples on silicon wafers, and conducting 64,128 , or 256 scans. FT-IR spectra were also obtained from attenuated total internal reflection (ATR) geometry using a Bruker Alpha Platinum ATR in the frequency range of $400-4000 \mathrm{~cm}^{-1}$ with a resolution of $4.0 \mathrm{~cm}^{-1}$. The samples were covered with a glass slide when the water content was to be analyzed. The ultraviolet-visible (UV-vis) absorption spectra were recorded on a Varian Carry 300 UV-vis double-beam spectrophotometer with a $600 \mathrm{~nm} / \mathrm{min}$ scan rate and a $1 \mathrm{~nm}$ data interval over a wavelength range from 200 to $800 \mathrm{~nm}$. Photoluminescence (PL) emission measurements were performed using a Varian Cary Eclipse fluorescence spectrophotometer operated at excitation wavelengths in the range of $350-525 \mathrm{~nm}$ in $25 \mathrm{~nm}$ increments. Known amounts of samples were dissolved in ethanol and placed into quartz cuvettes for $\mathrm{UV}-$ vis and PL measurements. The conductivity measurements were performed by using a Gamry G750 potentiostat/galvanostat operating at an ac voltage of $10 \mathrm{mV}$ and $100 \mathrm{kHz}$. The cell used for the conductivity measurements is a single fluorine-doped tin oxide (FTO)coated $2 \times 2 \mathrm{~cm}^{2}$ glass slide that was scratched using a diamond pen to create a straight line separating the two FTO domains (Figure S1). The cell constant was determined using a standard solution of $\mathrm{KCl}$ with a known conductivity value. The reference and counter (short cut) electrodes were attached to one side of the FTO-coated slide while the working electrode was attached to the other side and the sample filled the scratched region of the cell.

\section{RESULTS AND DISCUSSION}

A homogeneous mixture of sulfuric acid (SA) and 10-lauryl ether $\left(\mathrm{C}_{12} \mathrm{E}_{10}\right)$ and a small amount of water is in the LLC mesophase, where acid and of a little bit water was used as the solvent. The mesophase of $\mathrm{SA} / \mathrm{C}_{12} \mathrm{E}_{10}$ can be prepared as a gel by directly mixing concentrated SA and 10-lauryl ether $\left(\mathrm{C}_{12} \mathrm{E}_{10}\right)$ and some water or through a solution phase (simply using a solvent such as ethanol or water). The second method is an easy one and usually produces stable, clear gels of the SA/ $\mathrm{C}_{12} \mathrm{E}_{10}$ LLC mesophases upon evaporation of the solvent. However, the gels can be prepared by either mixing only SA and $\mathrm{C}_{12} \mathrm{E}_{10}$ and exposing to atmospheric water or by directly adding a required amount of water $\left(2.3-4.3 \mathrm{H}_{2} \mathrm{O} / \mathrm{SA}\right.$, see 
later) to the mixture. The preparation of a homogeneous sample in the gel phase has some difficulties, such as the SA/ $\mathrm{C}_{12} \mathrm{E}_{10}$ mixture without water produces carbon quantum dots (c-dots, see later) and adding the required amount of water increase the melting point $\left(70-125{ }^{\circ} \mathrm{C}\right)$ and makes homogenization difficult. Moreover, the mesophase forms over a very broad range of $\mathrm{SA} / \mathrm{C}_{12} \mathrm{E}_{10}$ mole ratio with a bicontinuous cubic (at low), 2D hexagonal (at intermediate), and micellar cubic mesostructures (at very high SA concentrations) similar to other LLC mesophases obtained using other solvents.

Figure 1 displays two POM images of the 2D hexagonal mesophases, prepared using both methods, as a gel and using a
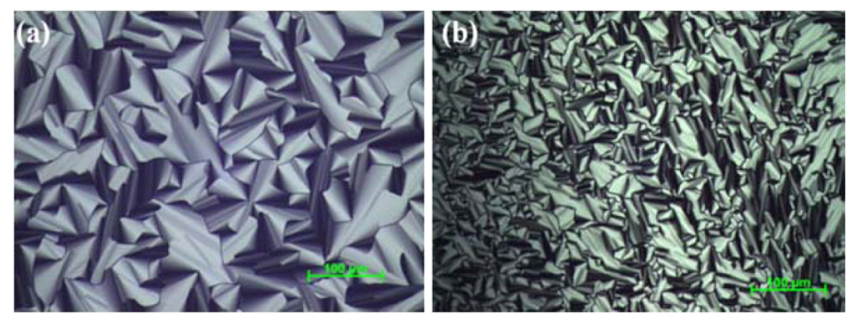

Figure 1. POM images of (a) the solution phase upon aging after spin coating over a microscope slide and (b) the fluidic viscous phase upon aging after spreading on a microscope slide.

clear solution phase. Clearly, both samples display a characteristic fan texture of the $2 \mathrm{D}$ hexagonal mesophase. However, the LLC mesophase formation, directly from the concentrated SA, is more problematic; approaching the same composition from the solution phase, by spreading the solution over a substrate and evaporating the solvent, is more convenient for obtaining clear LLC samples. This is because the samples, prepared from the solution phase, contain enough water to slow/stop the carbonization process. In both cases, the gel phase forms either by keeping some water or absorbing ambient water to stabilize. The typical water uptake is around 2.3-4.3 water molecules per SA, depending on the humidity and the acid content of the mesophase. However, at very low water contents, the mixture is less viscous and forms LLC phases upon absorption of the ambient water. The typical melting point of the gel rises to over $100{ }^{\circ} \mathrm{C}$ by absorbing the required amount of water.

Figure 2 shows a typical phase diagram of the $S A / C_{12} E_{10}$ over a broad range of $S A$ concentrations. The mesophase forms as low as $1 \mathrm{SA} / \mathrm{C}_{12} \mathrm{E}_{10}$ as a bicontinuous cubic phase, and it is stable up to an $11 \mathrm{SA} / \mathrm{C}_{12} \mathrm{E}_{10}$ mole ratio. The mesophase is hexagonal between a 2 and $3 \mathrm{~mol}$ ratio and micellar cubic from 4 to $11 \mathrm{~mol}$ ratio. The melting point gradually increases up to a $7 \mathrm{SA} / \mathrm{C}_{12} \mathrm{E}_{10}$ mole ratio and then decreases with further increases in the SA amount in the LLC mesophase. Above a $\mathrm{SA} / \mathrm{C}_{12} \mathrm{E}_{10}$ mole ratio of 11 , the samples are not stable and absorb more water, and the melting point gradually drops below RT; see the phase diagram in Figure 2. For instance the gels of $12 \mathrm{SA} / \mathrm{C}_{12} \mathrm{E}_{10}$ are fluidic at RT but diffract at small angles (Figure 3 ). Note also that this sample is a rigid gel upon cooling. The amount of water in the LLC media is also critical to the melting point and other physical properties. Therefore, more detailed phase diagrams are required to evaluate the full phase behaviors of the $\mathrm{SA} / \mathrm{C}_{n} \mathrm{E}_{m}$ systems.

To investigate the role of water, we also prepared a set of samples directly from a mixture of $\mathrm{SA}$ and $\mathrm{C}_{12} \mathrm{E}_{10}$ with various amounts of water. Figure S2 shows the pictures of these

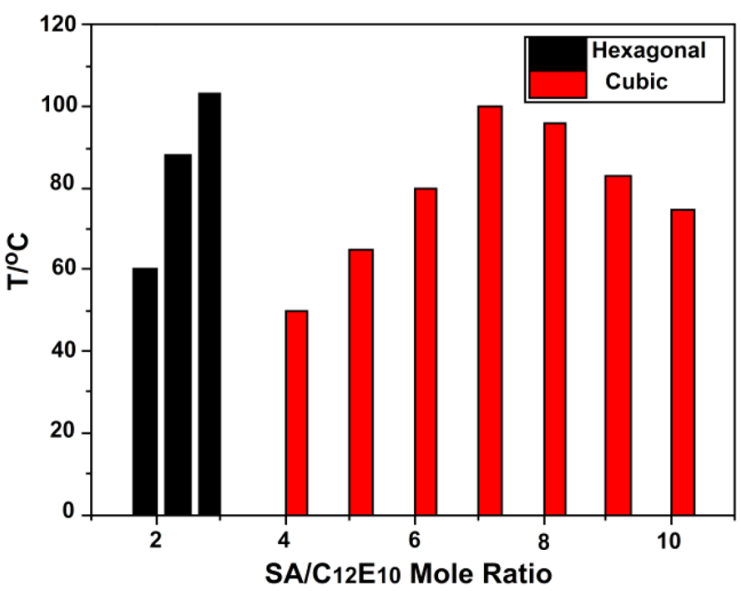

Figure 2. Representative phase diagram of the $S A / C_{12} E_{10} L L C$ mesophases of the most stable compositions with constant water content.

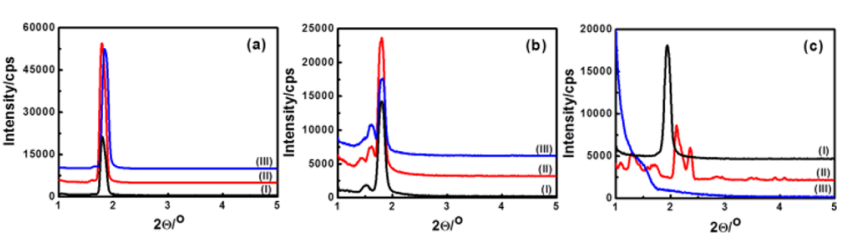

Figure 3. Small angle XRD pattern of LLC mesophases with different periods of aging and $\mathrm{SA} / \mathrm{C}_{12} \mathrm{E}_{10}$ mole ratio of (a) 3, (I) fresh, (II) 1 week, and (III) 1 month; (b) 4, (I) fresh, (II) 1 week and (III) 1 month; and (c) 12, (I) fresh, (II) $20 \mathrm{~min}$, and (III) 30 min old sample.

samples in the vials. Clearly, the amount of water is critical, the mixture is fluidic with $0 \mathrm{H}_{2} \mathrm{O} / \mathrm{SA}$ mole ratio (only water is coming from concentrated SA) that forms carbon quantum dots, but above $3.0 \mathrm{H}_{2} \mathrm{O} / \mathrm{SA}$ mole ratio the mixtures are gels (in the LLC mesophase) with clear appearances (Figure S2). Note also that the phase diagram in Figure 2 was constructed under ambient conditions (around $25 \% \mathrm{RH}$ and $22{ }^{\circ} \mathrm{C}$ ) at a water level where the mesophase is the most stable. In both preparation methods, the samples stabilize around the same water level, which has been monitored using an ATR-FTIR spectrometer, a sensitive balance, and ac conductivity measurements. Figure S3 shows the ATR-FTIR spectral changes, change in the mass in the sensitive balance, and conductivity changes of the samples prepared using both methods over time. In all three techniques, it has been observed that the change stops around a $2.3-4.3 \mathrm{H}_{2} \mathrm{O} / \mathrm{SA}$ mole ratio depending on the $\mathrm{SA} / \mathrm{C}_{12} \mathrm{E}_{10}$ mole ratio, except for the samples with an $\mathrm{SA} /$ $\mathrm{C}_{12} \mathrm{E}_{10}$ mole ratio of 12 and higher.

The mixture of a concentrated $\mathrm{SA}$ and $\mathrm{C}_{12} \mathrm{E}_{10}$ is isotropic at all compositions under the polarized optical microscope, but upon spreading over a glass substrate, over time, a well-defined fan texture appears at intermediate SA concentrations (Figure 1). However, the samples prepared using the appropriate amount of water $\left(1-5 \mathrm{H}_{2} \mathrm{O} / \mathrm{SA}\right.$ mole ratios) or using excess water where the mixture is liquid and its spin coating immediately produce a birefriengent thin film and displays a fan texture (Figure 1a). The XRD patterns of these samples are also consistent with this observation, while the fresh SA/C ${ }_{12} E_{10}$ mixture does not diffract at small angles; upon spreading over a glass substrate and aging for $5 \mathrm{~min}$ it provides a strong diffraction at around $2^{\circ}, 2 \theta$. This behavior is also observed under the polarized optical microscope; the freshly spread 
samples are usually dark between the crossed polarizers under the microscope, but upon absorbing ambient water, they become birefriengent and display small fanlike domains that grow over time into large fan textures (Figure 1b). However, the samples, spined over a glass substrate from the solution phase, diffract immediately after preparation (Figure 3a). The only change in the XRD pattern is an increase in the intensity of the diffraction line at around $2^{\circ}, 2 \theta$, over time. Since the fan texture in the POM image is characteristic of the $2 \mathrm{D}$ hexagonal mesostructure, the diffraction line likely originates from the (100) plane, providing a unit cell parameter of $55 \AA$, in the samples with a 2 to $3 \mathrm{SA} / \mathrm{C}_{12} \mathrm{E}_{10}$ mole ratio. Over a $4 \mathrm{SA} /$ $\mathrm{C}_{12} \mathrm{E}_{10}$ mole ratio, the mesophase becomes isotropic but diffracts at small angles, indicating a phase change from hexagonal to cubic (Figure $3 b$ ). The unit cell parameter, $a$, for this composition is $125 \AA$. At higher compositions the mesophase is isotropic (cubic), but these samples always display a single diffraction line which makes it difficult to index and determine if there is any further structural changes after increasing the amount of SA in the samples. Samples with an $\mathrm{SA} / \mathrm{C}_{12} \mathrm{E}_{10}$ of 12 and above are fluidic but display X-ray diffractions at small angles. Figure $3 \mathrm{c}$ shows the behavior of the sample with an $\mathrm{SA} / \mathrm{C}_{12} \mathrm{E}_{10}$ mole ratio of 12 , under the X-ray beam. It displays a time-dependent X-ray diffraction pattern, where the diffraction lines can be indexed to a cubic phase with a unit cell parameter, $a$, of $140 \AA$ (Figure 3c). Upon spreading this sample over a glass slide, one can observe only a highly intense diffraction line but over time, many new diffraction lines appear, and upon further aging, one can observe only a very broad diffraction at small angles. The intense line, upon spreading, is an indication of the orientation of the LLC phase that absorbs ambient water over time and undergoes reorganization to create highly ordered LLC domains and water-rich liquid domains. Further absorption of water creates a completely disordered fludic phase. Therefore, above a certain SA concentrations one must control the water level in the media.

Water uptake and water lost in the samples, prepared using no water and excess water, respectively, were monitored using a senstive balance, ATR-FTIR, and ac conductivity measurements to elucidate the role of water in the LLC mesophases. The water uptake is a very slow process that can be monitored using an ATR-FTIR spectrometer (Figure 4). The gel phase has a very broad band around $2000-3000 \mathrm{~cm}^{-1}$ due to stretching modes of a hydrogen-bonding network of $\mathrm{OH}$ groups of $\mathrm{SA}, \mathrm{H}_{3} \mathrm{SO}_{4}{ }^{+}, \mathrm{HSO}_{4}{ }^{-}$, and likely $\mathrm{H}_{3} \mathrm{O}^{+}$ions, surfactants, and initial water (Figures 4 and S4). The water bending mode is also broadly observed at around $1700 \mathrm{~cm}^{-1}$
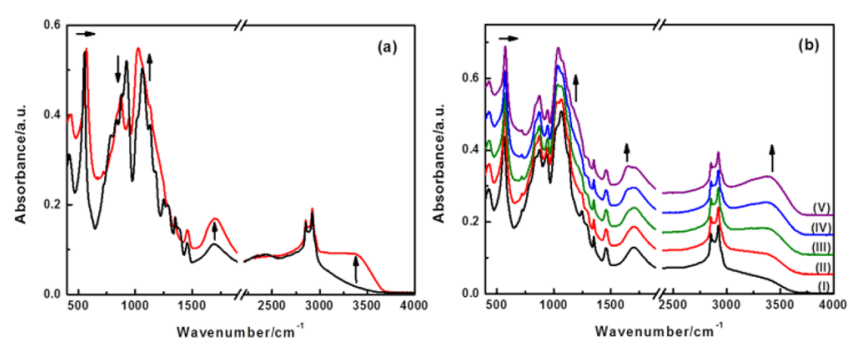

Figure 4. (a) FT-ATR spectra of the $4 \mathrm{SA} / \mathrm{C}_{12} \mathrm{E}_{10}$ mole ratio before (bottom) and after (top) absorbing ambient water and (b) a set of FTATR spectra of a sample with an $\mathrm{SA} / \mathrm{C}_{12} \mathrm{E}_{10}$ mole ratio of 3 and $\mathrm{H}_{2} \mathrm{O}$ / SA mole ratios of (I) 1, (II) 2, (III) 3, (IV) 4, and (V) 5 . and shifts to around $1640 \mathrm{~cm}^{-1}$ upon absorbing water. The water stretching band also evolves during water absorption (Figures 4 and S4). Both samples, prepared as a gel and from a solution phase, stabilize around the same water amounts that depend only on the SA amount in the samples and the humidity of the media. Figure S4(a) displays a series of ATR spectra of the fresh samples with various SA amounts. The freshly prepared samples display the most intense peak at around $927 \mathrm{~cm}^{-1}$ due to the $v-\mathrm{SO}_{4}$ mode of the undissociated $\mathrm{SA}$, and upon absorption of water, this peak almost disappears and a new peak at around $1027 \mathrm{~cm}^{-1}$ appears due to the $v-\mathrm{SO}_{4}$ mode of the $\mathrm{HSO}_{4}{ }^{-}$ion (Figure $\mathrm{S} 4(\mathrm{~b})$ ). Note that $\mathrm{SA}$ is a strong acid that dissociates completely in the presence of water into bisulfate and hydronium ions. These two peaks can be used to determine the water level of the samples. We also prepared five samples with various water contents, with a $\mathrm{H}_{2} \mathrm{O}$ / SA mole ratio of between 1 and 5 (Figure $4 \mathrm{~b}$ ). The spectrum recorded from the $\mathrm{H}_{2} \mathrm{O} / \mathrm{SA}$ with a mole ratio of 3 is very similar to the stabilized compositions by absorbing ambient water (Figure 4b). This is also consistent with our prediction from the other measurements (see later). Similar timedependent measurements were also performed using the SA, excess $\mathrm{H}_{2} \mathrm{O}$, and $\mathrm{C}_{12} \mathrm{E}_{10}$ solutions that lose water and form a mesophase with a similar composition (Figure S3(a)). One can monitor the loss of water and the evolution of the bisulfate ion. SA never forms in these samples unless they are dried at higher temperatures and at lower humidity.

Similarly, the water uptake in the $\mathrm{SA} / \mathrm{C}_{12} \mathrm{E}_{10}$ samples and the water release in $\mathrm{SA}-\mathrm{H}_{2} \mathrm{O}-\mathrm{C}_{12} \mathrm{E}_{10}$ can also be monitored using a four-digit balance and ac conductivity (Figures $5 \mathrm{a}$ and $\mathrm{S} 3(\mathrm{~b}, \mathrm{c})$ ).
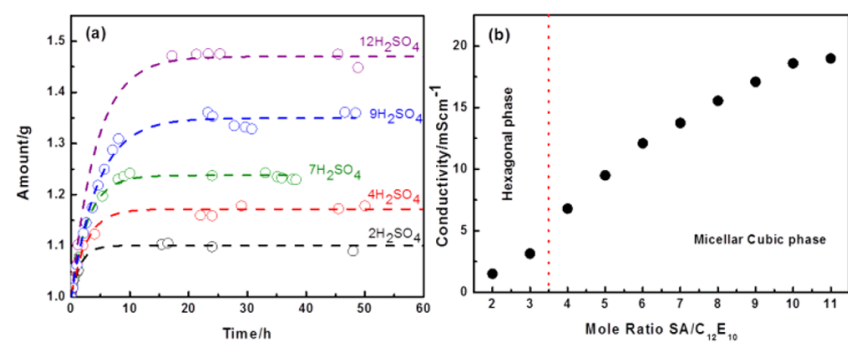

Figure 5. Change in (a) the weight and (b) the conductivity of the samples with an $\mathrm{SA} / \mathrm{C}_{12} \mathrm{E}_{10}$ mole ratio of between 2 and 11 .

Both weight change and ac conductivity stabilize at around the same water level; the only dependence is on the SA amount in the samples. Figure 5 shows the change in the weight and the ac conductivity of the samples with an $\mathrm{SA} / \mathrm{C}_{12} \mathrm{E}_{10}$ mole ratio of between 2 and 12 . Above a mole ratio of 11 , it is difficult to control the water uptake of the samples. However, below a mole ratio of 12 , the control is very good; water uptake or release stops at around the same $\mathrm{H}_{2} \mathrm{O} / \mathrm{SA}$ mole ratio (Figure $5 a)$. The ac conductivity also gradually increases with an increasing SA amount in the mesophase, where the highest conductivity is observed from an $11 \mathrm{SA} / \mathrm{C}_{12} \mathrm{E}_{10}$ mole ratio as high as $19 \mathrm{mS} / \mathrm{cm}$ (Figure $5 \mathrm{~b}$ ). Moreover, it is possible to prepare the LLC mesophases at different $\mathrm{H}_{2} \mathrm{O} / \mathrm{SA}$ mole ratios.

Here, we also demonstrate the use of the $\mathrm{SA} / \mathrm{C}_{12} \mathrm{E}_{10} \mathrm{LLC}$ mesophases as a medium for organic and inorganic reactions. For example, we demonstrate the synthesis of highly efficient photoluminescent carbon quantum dots (c-dots) and highly proton conducting mesostructured silica films and monoliths. SA is a well-known acid used as a dehydration source for 
hydrocarbons to form carbon black. The mixture of SA and $\mathrm{C}_{12} \mathrm{E}_{10}$ slowly undergoes a carbonization process and forms carbon quantum dots. The acid and surfactant mixture undergoes changes from clear to light yellow and then to brown and finally to a dark-brown gel over time. This process has been monitored using UV-vis absorption and photoluminescence (PL) spectral measurements. Figure 6a shows a
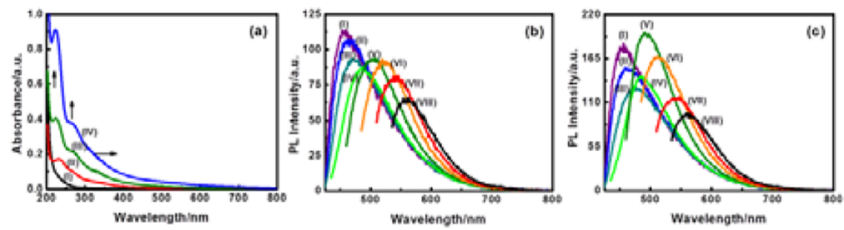

Figure 6. (a) UV-vis absorption spectra of (I) pure $\mathrm{C}_{12} \mathrm{E}_{10}$ and the sample with a $3 \mathrm{SA} / \mathrm{C}_{12} \mathrm{E}_{10}$ mole ratio, (II) fresh, and aged for (III) $1 \mathrm{~h}$ at $80{ }^{\circ} \mathrm{C}$ and for (IV) $2 \mathrm{~h}$ at $80^{\circ} \mathrm{C}$. (b) Photoluminescence spectra of the sample with a $3 \mathrm{SA} / \mathrm{C}_{12} \mathrm{E}_{10}$ mole ratio, treated at $80^{\circ} \mathrm{C}$ for $2 \mathrm{~h}$ with $50 \mathrm{mg}$ dissolved in $1 \mathrm{~mL}$ of ethanol. (c) Photoluminescence spectra of the sample with an $\mathrm{SA} / \mathrm{C}_{12} \mathrm{E}_{10}$ mole ratio of 6 , treated at RT for 3 months and $12.5 \mathrm{mg}$ dissolved in $1 \mathrm{~mL}$ of ethanol. The excitation wavelengths are (I) 350, (II) 375, (III) 400, (IV) 425, (V) 450, (VI) 475, (VII) 500, and (VIII) $525 \mathrm{~nm}$.

set of absorption spectra, recorded during the carbonization process under various conditions. The absorption spectrum in the visible region gradually evolves in intensity, and the absorption edge shifts to higher wavelengths over time, indicating an increase in the c-dot density and growth, respectively. The growth can be enhanced by heating the samples below the combustion temperatures and also can be stopped almost completely by increasing the water content of the media, also indicating that the process is a dehydration process. The mixture of $\mathrm{SA}$ and $\mathrm{C}_{12} \mathrm{E}_{10}$, with aging, also displays bright white light upon illumination under a UV light source. Figure $6 \mathrm{~b}, \mathrm{c}$ shows a set of PL spectra at various excitation frequencies of two different compositions. It is clear from the trend that by aging the mixture of $\mathrm{SA}$ and $\mathrm{C}_{12} \mathrm{E}_{10}$ larger c-dots form (Figure 6). Notice also that the PL is characterstic of the c-dots and comparable to the c-dots, obtained by a variety of other methods. ${ }^{33-40}$ Similar to the absorption edge, the most intense PL also shifts to a lower frequency over time, also indicating the growth of the c-dots. The $\mathrm{SA} / \mathrm{C}_{12} \mathrm{E}_{10}$ samples in all compositions produce c-dots and form a liquid-crystalline phase at any time during the carbonization process if enough water is introduced into the media (Figure S5). The carbonization process can be enhanced or reduced by simply controlling the amount of water in the media.

As a second example, we demonstrate the use of the SA/ $\mathrm{C}_{12} \mathrm{E}_{10}$ mesophase as a template to synthesize mesostructured highly proton conducting silica thin films and monoliths. A set of clear solutions were prepared by changing only the SA and TEOS concentrations in the media. The SA concentration has been chosen to be $2,4,6$, and 8 , and the TEOS concentration has been chosen to be $1,3,5$, and 7 for each $\mathrm{C}_{12} \mathrm{E}_{10}$, respectively, and a total of 16 samples were prepared and labeled as $\mathrm{H}_{x} \mathrm{~S}_{y}$ (where $\mathrm{H}$ and $\mathrm{S}$ represent acid and silica, respectively, and $x$ and $y$ are the acid and TEOS mole ratios in the samples).

All compositions produced mesostructured, well-oriented, highly transparent films with excellent proton conductivity. Figure 7 shows a set of XRD patterns recorded from the films. All thin films display an intense diffraction line at around $2^{\circ}, 2 \theta$
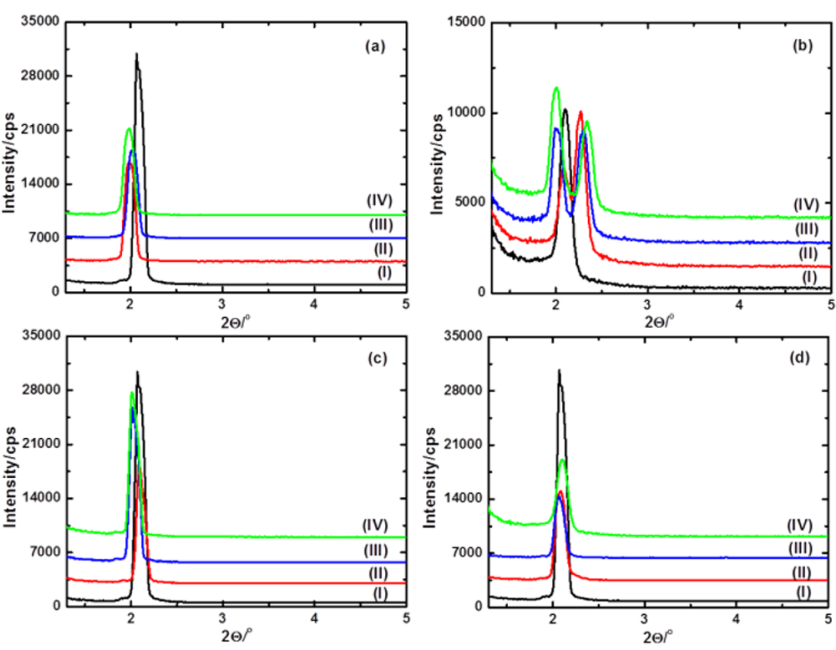

Figure 7. Small-angle XRD patterns of the thin films, prepared using different SA/TEOS mole ratios, by aging. (a) $\mathrm{SA} / \mathrm{C}_{12} \mathrm{E}_{10}=2$, TEOS/ $\mathrm{C}_{12} \mathrm{E}_{10}=1$, (I) fresh, (II) 1 day, (III) 3 days, and (IV) 1 week old. (b) $\mathrm{SA} / \mathrm{C}_{12} \mathrm{E}_{10}=2$, TEOS $/ \mathrm{C}_{12} \mathrm{E}_{10}=7$, (I) fresh, (II) 1 day, (III) 3 days, and (IV) 1 week old. (c) TEOS $/ \mathrm{C}_{12} \mathrm{E}_{10}=1$ and SA/C $\mathrm{C}_{12} \mathrm{E}_{10}$ is (I) 2, (II) 4 , (III) 6 , and (IV) 8. (d) SA/C $\mathrm{C}_{12} \mathrm{E}_{10}=2$ and TEOS $/ \mathrm{C}_{12} \mathrm{E}_{10}$ is (I) 1, (II) 3, (III) 5, and (IV) 7.

and remain stable over aging. Only higher silica and lower SA samples leach out some surfactant and acid that form an LLC mesophase over the films. Those samples undergo phase separation driven by the condensation of the silica walls in the mesostructure. The phase separation is observed as two distant lines at around $2^{\circ}$ and $2.2^{\circ}, 2 \theta$ (Figure $7 \mathrm{~b}$ ). During aging, the lower-angle line retains its position, but the high-angle line appears over time and gradually shifts to higher angles with aging. This is consistent with the above proposal that the mesostructure undergoes condensation and causes a shrinkage of the mesostructures, as a result leaching out some of the surfactant and SA from the pores. However, at low silica and also at high SA concentrations the mesostructure is stable; no phase separation has been recorded (cf. XRD patterns in Figure 7).

A similar approach has been reported by Ozin et al. using triflic acid in an aqueous medium to form proton-conducting mesostructured silica. ${ }^{41}$ However, the reported conductivty is around $10^{-7} \mathrm{~S} / \mathrm{cm}$ under ambient conditions (similar to our conditions). Also note that the triflic acid is volitile and evaporates over time from the pores; therefore, the conductivity decreases further with aging. It is also worth mentioning that there are commendable reports on the surface modification of mesoporous silica with sulfonic acid groups gaining high proton conductivity. ${ }^{42,43}$ The reported values exceed $5.4 \mathrm{mS} / \mathrm{cm}$ under ambient conditions. ${ }^{43}$ However, the materials require tedious preparation methods.

We also collected the ac conductivity of these samples by placing a few drops of the clear solution over a special cell, designed over a $2 \times 2 \mathrm{~cm}^{2}$ FTO glass (Figure S1). Table 1 shows the ac conductivity values of the same samples with different compositions and aging periods. All samples display high proton conductivity, as high as $19.3 \mathrm{mS} / \mathrm{cm}$. In general, with an increasing SA amount at a constant TEOS $/ \mathrm{C}_{12} \mathrm{E}_{10}$ ratio the conductivity also increases; however, increasing the TEOS amount reduces the conductivity in all samples. Also note that the conductivity gradually increases with aging at all compositions. This can be interpreted as the formation of an 
Table 1. Conductivity Values $(\mathrm{mS} / \mathrm{cm})$ of the Mesostructured $\mathrm{SA} / \mathrm{SiO}_{2}$ Thin Films with Various Acid and Silica Amounts ${ }^{a}$

$\begin{array}{ccccc}\text { aging time/samples } & \text { fresh } & 1 \text { day } & 3 \text { days } & 7 \text { days } \\ \mathrm{H}_{2} \mathrm{~S}_{1} & 1.1 & 1.4 & 2.5 & 2.7 \\ \mathrm{H}_{2} \mathrm{~S}_{3} & 0.4 & 0.8 & 1.4 & 2.2 \\ \mathrm{H}_{2} \mathrm{~S}_{5} & 0.2 & 0.5 & 0.9 & 1.6 \\ \mathrm{H}_{2} \mathrm{~S}_{7} & 0.1 & 0.4 & 0.4 & 1.1 \\ \mathrm{H}_{4} \mathrm{~S}_{1} & 4.0 & 9.0 & 13.0 & 14.7 \\ \mathrm{H}_{4} \mathrm{~S}_{3} & 2.3 & 5.9 & 9.3 & 10.5 \\ \mathrm{H}_{4} \mathrm{~S}_{5} & 0.9 & 3.2 & 5.5 & 6.0 \\ \mathrm{H}_{4} \mathrm{~S}_{7} & 0.7 & 4.3 & 8.3 & 8.8 \\ \mathrm{H}_{6} \mathrm{~S}_{1} & 9.3 & 13.0 & 13.0 & 14.5 \\ \mathrm{H}_{6} \mathrm{~S}_{3} & 8.5 & 12.9 & 13.8 & 14.4 \\ \mathrm{H}_{6} \mathrm{~S}_{5} & 7.0 & 9.8 & 10.4 & 11.8 \\ \mathrm{H}_{6} \mathrm{~S}_{7} & 4.8 & 8.0 & 9.4 & 10.6 \\ \mathrm{H}_{8} \mathrm{~S}_{1} & 13.9 & 16.2 & 16.5 & 19.3 \\ \mathrm{H}_{8} \mathrm{~S}_{3} & 11.3 & 16.5 & 17.4 & 17.3 \\ \mathrm{H}_{8} \mathrm{~S}_{5} & 11.4 & 13.9 & 16.1 & 16.9 \\ \mathrm{H}_{8} \mathrm{~S}_{7} & 8.8 & 12.7 & 12.0 & 14.5\end{array}$

${ }^{a} \mathrm{H}$ stands for sulfuric acid, $\mathrm{S}$ stands for silica, and the numbers are SA/ $\mathrm{C}_{12} \mathrm{E}_{10}$ and $\mathrm{SiO}_{2} / \mathrm{C}_{12} \mathrm{E}_{10}$ mole ratios.

LLC mesophase (due to phase separation) that usually has higher conductivity values or the absorption of extra water or the further condensation of the silica that hinders the nanodomains, where the confinement effect also plays a role in the conductivity. To elucidate the origin of higher conductivity upon aging, we also monitored the aging process using FTIR spectroscopy of two samples with low and high silica amounts and found that there is almost no change in the water amount in both samples over a long period of time. This observation rules out the possibility of extra water absorption of the samples over time. However, a more detailed investigation is required to further elucidate the origin. Aging these samples under dry conditions also promotes the carbonization process and produces a highly PL mesostructured c-dot embedded silica thin film or monolith. Therefore, one has to be careful with high-temperature anealing or should use it under ambient or high humidity conditions.

\section{CONCLUSIONS}

The mixture of $\mathrm{SA}$ and $\mathrm{C}_{12} \mathrm{E}_{10}$ forms lyotropic liquid-crystalline mesophases over a broad range of compositions with the help of as little as $1 \mathrm{H}_{2} \mathrm{O} / \mathrm{SA}$. The mesophase is hexagonal at low $\mathrm{SA} / \mathrm{C}_{12} \mathrm{E}_{10}$ mole ratios and cubic at higher compositions. The melting point of the mesophase is sensitive to both the SA and $\mathrm{H}_{2} \mathrm{O}$ contents of the media. However, certain water amounts at a constant temperature and humidity are fixed at around 2.3$4.3 \mathrm{H}_{2} \mathrm{O} / \mathrm{SA}$, which does not change upon aging. The conductivity increases with increasing SA amounts in the mesophase.

The $\mathrm{SA} / \mathrm{C}_{12} \mathrm{E}_{10} / \mathrm{H}_{2} \mathrm{O}$ LLC mesophases can be used as a medium to produce photoluminescent $\mathrm{c}$-dots in which the preprepared c-dots are usually incorporated into the LLC media. The amount and the size of the c-dots can be simply controlled by controlling the reaction conditions, such as time, temperature, and humidity. The LLC mesophases have also been used to produce SA-embedded mesostructured silica films with excellent proton conductivity; the proton conductivity can be simply controlled by controlling the SA amount in the mesophase and mesostructured silica films. Overall, the SA/
$\mathrm{C}_{12} \mathrm{E}_{10}$ phases can provide a convenient strong acidic medium for many other reactions and can also be used as a protonconducting membrane in various renewable energy applications.

\section{ASSOCIATED CONTENT}

S Supporting Information

The Supporting Information is available free of charge on the ACS Publications website at DOI: 10.1021/acs.langmuir.5b02225.

Additional FTIR spectra, photographs of the samples in vials with and without UV illumination, FTO cells with and without sample, and a schematic representation of the FTO cell used for measurements of conductivity (PDF)

\section{AUTHOR INFORMATION}

\section{Corresponding Author}

*E-mail: dag@fen.bilkent.edu.tr.

\section{Author Contributions}

The manuscript was written through the contributions of all authors. All authors have given approval to the final version of the manuscript.

Notes

The authors declare no competing financial interest.

\section{ACKNOWLEDGMENTS}

We thank TÜBİTAK under project number $113 \mathrm{Z} 730$ for financial support. Ö.D. is a member of the Science Academy, Istanbul, Turkey.

\section{ABBREVIATIONS}

LLC, lyotropic liquid crystal; FTO, fluoride-doped tin dioxide; SA, sulfuric acid; TEOS, tetraethylortosilicate

\section{REFERENCES}

(1) Mitchell, D. J.; Tiddy, G. J. T.; Waring, L.; Bostock, T.; McDonald, M. P. Phase behavior of polyoxyethylene surfactants with water. Mesophase structures and partial miscibility (cloud points). J. Chem. Soc., Faraday Trans. 1 1983, 79, 975-1000.

(2) Blackmore, E. S.; Tiddy, G. J. T. Phase behaviour and lyotropic liquid crystals in cationic surfactant-water systems. J. Chem. Soc., Faraday Trans. 2 1988, 84, 1115-1127.

(3) Dong, R.; Hao, J. Complex fluids of poly(oxyethylene) monoalkyl ether nonionic sur- factants. Chem. Rev. 2010, 110, 4978-5022.

(4) Alexandridis, P.; Zhou, D.; Khan, A. Lyotropic liquid crystallinity in amphiphilic block copolymers: temperature effects on phase behavior and structure for poly(ethylene oxide)-b-poly(propylene oxide)-b-poly(ethylene oxide) copolymers of different composition. Langmuir 1996, 12, 2690-2700.

(5) Alexandridis, P.; Olsson, U.; Lindman, B. A record nine different phases (four cubic, two hexagonal, and one lamellar lyotropic liquid crystalline and two micellar solutions) in a ternary isothermal system of an amphiphilic block copolymer and selective solvents (water and oil). Langmuir 1998, 14, 2627-2638.

(6) Hollamby, M. J.; Trickett, K.; Mohamed, A.; Eastoe, J.; Rogers, S. E.; Heenan, K. Surfactant aggregation in $\mathrm{CO}_{2} /$ Heptane solvent mixtures. Langmuir 2009, 25, 12909-12913.

(7) Firestone, M. A.; Dzilawa, J. A.; Zapo, P.; Curtiss, L. A.; Seifert, S.; Dietz, M. L. Lyotropic liquid-crystalline gel formation in a room temperature ionic liquid. Langmuir 2002, 18, 7258-7260.

(8) Araos, M. U.; Warr, G. G. Self-assembly of nonionic surfactants into lyotropic liquid crystals in ethylammonium nitrate, a room temperature ionic liquid. J. Phys. Chem. B 2005, 109, 14275-14277. 
(9) Ichikawa, T.; Yoshio, M.; Hamasaki, A.; Mukai, T.; Ohno, H.; Kato, T. Self-organization of room temperature ionic liquids exhibiting liquid crystalline bicontinuous cubic phases: Formation of nano-ion channel networks. J. Am. Chem. Soc. 2007, 129, 10662-10663.

(10) Greaves, T. L.; Drummond, C. J. Ionic liquids as amphiphile self-assembly media. Chem. Soc. Rev. 2008, 37, 1709-1726.

(11) Çelik, Ö.; Dag, Ö. A new lyotropic liquid crystalline system:oligo(ethylene oxide) surfactants with $\mathrm{M}\left(\mathrm{H}_{2} \mathrm{O}\right)_{\mathrm{n}} \mathrm{X}_{\mathrm{m}}$ transition metal complexes. Angew. Chem., Int. Ed. 2001, 40, 3800-3803.

(12) Albayrak, C.; Özkan, N.; Dag, Ö. Origin of lyotropic liquid crystalline mesophase formation and liquid crystalline to mesostructured solid transformation in the metal nitrate salt-surfactant systems. Langmuir 2011, 27, 870-873.

(13) Albayrak, C.; Cihaner, A.; Dag, Ö. A highly conductive lithium salts-non-ionic surfactants lyotropic liquid crystalline mesophases and its application. Chem. - Eur. J. 2012, 18, 4190-4193.

(14) Albayrak, C.; Barım, G.; Dag, Ö. Effect of hygroscopicity of the metal salt on the formation and air stability of lyotropic liquid crystalline mesophases in hydrated salt-surfactant systems. J. Colloid Interface Sci. 2014, 433, 26-33.

(15) Barım, G.; Albayrak, C.; Yilmaz, E.; Dag, Ö. Highly conductive lyotropic liquid crystalline mesophases of pluronics (P65, P85, P103, and $\mathrm{P} 123)$ and hydrated salts $\left(\mathrm{LiCl}\right.$ and $\left.\mathrm{LiNO}_{3}\right)$. Langmuir 2014, 30, 6938-6945.

(16) Tunkara, E.; Albayrak, C.; Polat, E. O.; Kocabas, C.; Dag, Ö. Highly proton conductive phosphoric acid-nonionic surfactant lyotropic liquid crystalline mesophases and application in graphene optical modulators. ACS Nano 2014, 8, 11007-11012.

(17) Attard, G. S.; Glyde, J. C.; Göltner, C. G. Liquid-crystalline phases as templates for the synthesis of mesoporous silica. Nature 1995, 378, 366-368.

(18) Yamauchi, Y.; Momma, T.; Yokoshima, T.; Kuroda, K.; Osaka, T. Highly ordered mesostructured $\mathrm{Ni}$ nanoparticles prepared from lyotropic liquid crystals by electroless deposition: the effect of reducing agents on the ordering of mesostructure. J. Mater. Chem. 2005, 15, 1987-1994.

(19) Xu, Y.; Gu, W.; Gin, D. L. Heterogeneous catalysis using a nanostructured solid acid resin based on lyotropic liquid crystals. J. Am. Chem. Soc. 2004, 126, 1616-1617.

(20) Dellinger, T. M.; Braun, P. V. Lyotropic liquid crystals as nanoparticle synthesis. Chem. Mater. 2004, 16, 2201-2207.

(21) Soberats, B.; Yoshio, M.; Ichikawa, T.; Taguchi, S.; Ohno, H.; Kato, T. 3D anhydrous proton-transporting nanochannels formed by self-assembly of liquid crystals composed of a sulfobetaine and a sulfonic acid. J. Am. Chem. Soc. 2013, 135, 15286-15289.

(22) Yamauchi, Y. Field-induced alignment control of one-dimensional mesochannels in mesoporous materials. J. Ceram. Soc. Jpn. 2013, $121,831-840$.

(23) Sugimoto, W.; Makino, S.; Mukai, R.; Tatsumi, Y.; Fukuda, Y.; Takasu, Y.; Yamauchi, Y. Synthesis of ordered mesoporous ruthenium by lyotropic liquid crystals and its electrochemical conversion to mesoporous ruthenium oxide with high surface area. J. Power Sources 2012, 204, 244-248.

(24) Depierro, M. A.; Guymon, C. A. Polymer structure development in lyotropic liquid crystalline solutions. Macromolecules 2014, 47, $5728-5738$.

(25) Attard, G. S.; Barlett, P. N.; Coleman, N. R. B.; Elliott, J. M.; Owen, J. R. Lyotropic liquid crystalline properties of non-ionic surfactant $/ \mathrm{H}_{2} \mathrm{O} /$ hexachloroplatinic acid ternary mixtures used for the production of nanostructured platinum. Langmuir 1998, 14, 73407342.

(26) Nakano, M.; Teshigawara, T.; Sugita, A.; Leesajakul, W.; Taniguchi, A.; Kamo, T.; Matsuko, H.; Handa, T. Dispersion of liquid crystalline phases of the monolein/oleic acid/pluronic 127 system. Langmuir 2002, 18, 9283-9288.

(27) Negrini, R; Fong, W. K.; Boyd, B. J.; Mezzenga, R. pHresponsive lyotropic liquid crystals and their potential therapeutic role in cancer treatment. Chem. Commun. 2015, 51, 6671-6674.
(28) Peng, H.; Sejdic, J. T. Simple aqueous solution route to luminescent carbogenic from carbohydrates. Chem. Mater. 2009, 21, $5563-5565$

(29) Zhang, J.; Shen, W.; Pan, D.; Zhang, Z.; Fang, Y.; Wu, M. Controlled synthesis of green and blue luminescent carbon nanoparticles with high yields by carbonization of sucrose. New J. Chem. 2010, 34, 591-593.

(30) Li, H.; Kang, Z.; Liu, Y.; Lee, S. T. Carbon nanodots: synthesis, properties and applications. J. Mater. Chem. 2012, 22, 24230-24253.

(31) Zhang, Z.; Zhang, J.; Qu, L. Graphene quantum dots: an emerging material for energy-related applications and beyond. Energy Environ. Sci. 2012, 5, 8869-8890.

(32) Dai, L.; Chang, D. W.; Baek, J. B.; Lu, W. Carbon nanomaterials for advanced energy conversion and storage. Small 2012, 8, 11301166.

(33) Sun, Y. P.; Zhou, B.; Wang, W.; Fernando, K. A. S.; Pathak, P.; Meziani, M. J.; Harruff, B. A.; Wang, X.; Wang, H.; Luo, P. G.; Yang, H.; Kose, M. E.; Chen, B.; Veca, L. M.; Xie, S. Y. Quantum-sized carbon dots for bright and colorful photoluminescence. J. Am. Chem. Soc. 2006, 128, 7756-7757.

(34) Liu, R.; Wu, D.; Liu, S.; Koynov, K.; Knoll, W.; Li, Q. An aqueous route to multicolor photoluminescent carbon dots using silica spheres as carriers. Angew. Chem. 2009, 121, 4668-4671.

(35) Lu, J.; Yang, J. X.; Wang, J. Z.; Lim, A.; Wang, S.; Loh, K. P. One-pot synthesis of fluorescent carbon nanoribbons, nanoparticles, and graphene by the exfoliation of graphite in ionic liquids. ACS Nano 2009, 3, 2367-2375.

(36) Wang, F.; Pang, S.; Wang, L.; Li, Q.; Kreiter, M.; Liu, C. Y. One step synthesis of highly luminescent carbon dots in noncoordinating solvents. Chem. Mater. 2010, 22, 4528-4530.

(37) Bourlinos, A. B.; Zboril, R.; Petr, J.; Bakandiritsos, A.; Krysmann, M.; Giannelis, E. P. Luminescent surface quaternized carbon dots. Chem. Mater. 2012, 24, 6-8.

(38) Fernando, K. A.; Sahu, S.; Liu, Y.; Lewis, W. K.; Guliants, E. A.; Jafariyan, A.; Wang, P.; Bunker, C. E.; Sun, Y. P. Carbon quantum dots and application in photocatalytic energy conversion. ACS Appl. Mater. Interfaces 2015, 7, 8363-8376.

(39) Huang, X.; Tan, C.; Yin, Z.; Zhang, H. Hybrid nanostructures based on two-dimensional nanomaterials. Adv. Mater. 2014, 26, 21852204.

(40) Ariga, K.; Yamauchi, Y.; Rydzek, G.; Ji, Q.; Yonamine, Y.; Wu, K. C. W.; Hill, J. P. Layer-by-layer nanoarchitectonics: invention, innovation, and evolution. Chem. Lett. 2014, 43, 36-68.

(41) Halla, J. D.; Mamak, M.; Williams, D. E.; Ozin, G. A. Meso$\mathrm{SiO}_{2}-\mathrm{C}_{12} \mathrm{EO}_{10} \mathrm{OH}-\mathrm{CF}_{3} \mathrm{SO}_{3} \mathrm{H}-\mathrm{a}$ novel proton-conducting solid electrolyte. Adv. Funct. Mater. 2003, 13, 133-138.

(42) Marschall, R.; Rathousky, J.; Wark, M. Ordered functionalized silica materials with high proton conductivity. Chem. Mater. 2007, 19, 6401-6407.

(43) Fujita, S.; Koiwai, A.; Kawasumi, M.; Inagaki, S. Enhancement of transport by high densification of sulfonic acid groups in highly ordered mesoporous silica. Chem. Mater. 2013, 25, 1584-1591. 